\title{
Article
}

\section{The Diffusion Role in Adsorption of Hexavalent Chromium on Solid Olive Mill Waste}

\author{
Gennaro Bufalo ${ }^{1}$, Francesca Di Nezza ${ }^{2}$, Marco Perna ${ }^{3}$, Stefano Salvestrini ${ }^{4}$ (D) and Luigi Ambrosone ${ }^{3, *(1)}$ \\ 1 Department of Naples, INAIL-Sector Research, Certification and Verification, I-80121 Naples, Italy; \\ g.bufalo@inail.it \\ 2 Department of Agricultural and Environmental Sciences, Via Amendola, 165A, 70126 Bari, Italy; \\ francesca.dinezza@uniba.it \\ 3 Department of Medicine and Health Sciences "V. Tiberio", University of Molise, 86100 Campobasso, Italy; \\ marco.perna@unimol.it \\ 4 Department of Environmental, Biological and Pharmaceutical Sciences and Technologies, University of \\ Campania “Luigi Vanvitelli", via Vivaldi 43, 81100 Caserta, Italy; stefano.salvestrini@unicampania.it \\ * Correspondence: ambroson@unimol.it
}

check for updates

Citation: Bufalo, G.; Di Nezza, F.; Perna, M.; Salvestrini, S.; Ambrosone, L. The Diffusion Role in Adsorption of Hexavalent Chromium on Solid Olive Mill Waste. Appl. Sci. 2021, 11, 3096. https://doi.org/10.3390/ app11073096

Academic Editor: Prashant Kumar

Received: 12 February 2021

Accepted: 29 March 2021

Published: 31 March 2021

Publisher's Note: MDPI stays neutral with regard to jurisdictional claims in published maps and institutional affiliations.

Copyright: (c) 2021 by the authors. Licensee MDPI, Basel, Switzerland. This article is an open access article distributed under the terms and conditions of the Creative Commons Attribution (CC BY) license (https:// creativecommons.org/licenses/by/ $4.0 /)$.

\begin{abstract}
The removal of $\mathrm{Cr}(\mathrm{VI})$ ions from aqueous solutions with wet pomace treated with laponite was investigated. A direct comparison with untreated biomass revealed an increase in both the rate of adsorption and the amount adsorbed. A cooperative interaction between the laponite platelets and biomass surface making more adsorption sites accessible was suggested. In this process, a key role is played by intraparticle diffusion. The experimental results indicate that intraparticle diffusion plays an important role in the adsorption process. A simple diffusion-binding model is presented to discuss the experimental results. The diffusion lifetime is linearly related to the adsorbent mass. The model combined with experimental results allowed us to estimate the average free path of a $\mathrm{Cr}(\mathrm{VI})$ molecule. Particularly, it was obtained that, in $1 \mathrm{dm}^{3}$ of solution, the diffusion path increased by nearly $1 \mathrm{~cm}$ per gram of adsorbent. However, this did not imply that the amount of $\mathrm{Cr}(\mathrm{VI})$ removed decreased because the total number of adsorption sites also increased.
\end{abstract}

Keywords: chromium (VI) ions; intraparticle diffusion; laponite; olive mill waste

\section{Introduction}

The majority of consumable vegetable oils must be refined in order to eliminate undesirable substances affecting the quality of the oil. On the contrary, the quality of olive oil in terms of free fatty acids makes its refining unnecessary and the oil can be consumed as "virgin olive oil" [1]. Virgin olive oil is produced by the mechanical pressing of olive fruits and the olive oil is released from the oil bodies of the fruits, and together with many other ingredients, forms the bulk olive oil [2]. The malaxation step aims to destroy the oil bodies (inner structure of the olives acting as tiny reservoirs) and liberate the oil. After the first pressing of the olives remains a mixture of the pulp and stones of olives, which constitute the solid olive mill waste. Many reports indicate that such residue is a combustion material for heating, due to its content of cellulose, hemicellulose and lignin [3-6]. It was also reported that olive mill waste has good adsorbing capacity of heavy metals [7-9].

It is well known that the uncontrolled disposal of olive mill waste produces severe environmental problems. In order to prevent serious damage to the environment, various alternatives can be adopted. With this in mind, in recent years we investigated the ability of solid olive mill waste to adsorb heavy metals and in particular $\mathrm{Cr}(\mathrm{VI})$. The adsorption process is affected by the chemical composition of biomass as well as its surface characteristics. On the other hand, several experimental investigations have established good potentiality for the composites of solid olive mill waste clays to be used as adsorbent for the removal of pollutants from wastewater [10-12]. Furthermore, various types of nanoclays 
such as kaolinite nanosheets and halloysite nanotubes have become important targets for applications in bioremediation [13].

In this study, the adsorption behavior of solid olive mill waste treated with laponite was investigated. The research had a dual purpose: on the one hand, to analyze the adsorption of the treated biomass; and on the other hand, how a highly plastic synthetic clay [14] modifies the surface of organic residue. In this study, the ability of solid olive mill waste treated with laponite (LAP) to adsorb chromium (VI) from aqueous solutions was investigated. The first objective was addressed by directly comparing the amount of $\mathrm{Cr}(\mathrm{VI})$ adsorbed on equal quantities of treated and untreated biomass. The second was approached by analyzing the role of intraparticle diffusion in the adsorption process. The experimental results were interpreted on the basis of a simple binding-diffusion model to justify the evidence of a reinforced adsorption capacity towards $\mathrm{Cr}(\mathrm{VI})$.

\section{Materials and Methods}

\subsection{Chemicals}

Laponite RD, i.e., the synthetic hectorite of chemical formula $\mathrm{Na}_{0.7}^{+}\left[\mathrm{Si}_{8} \mathrm{Mg}_{5.5} \mathrm{O}_{20}(\mathrm{OH})_{4}\right]^{-0.7}$, manufactured by Rockwood Additives BYK, was kindly offered for this research. Potassium chromate $\left(\mathrm{K}_{2} \mathrm{CrO}_{4}\right)$ (assay > 95\%) from Carlo Erba Reagents, Milan Italy. Both chemical products were used without further purification for all experiments.

\subsection{Biomass}

The biomass, used for adsorption investigations, was wet pomace produced by a laboratory miniplant with a capacity from 50 to $100 \mathrm{~kg} \cdot \mathrm{h}^{-1}(\mathrm{OLIOMIO}$, Toscana Enologica Mori). The material was a pulpy matter containing oil, water, small pieces of kernels, pulp debris and pieces of leaves. It was immediately stored at $18{ }^{\circ} \mathrm{C}$ until use. Hereafter, it will be referred to as biomass WP.

\subsection{Preparation of $\mathrm{Cr}(\mathrm{VI})$ Stock Solution}

A stock solution of $\mathrm{K}_{2} \mathrm{CrO}_{4}$ was prepared by dissolving $0.0750 \mathrm{~g}$ in $0.500 \mathrm{dm}^{3}$ of ultra pure water (UPW). The stock solution was designed to have a metallic chromium $(\mathrm{Cr})$ concentration of $40 \mathrm{mg} \cdot \mathrm{dm}^{-3}$. The $\mathrm{pH}$ of stock solution was 7.60. For batch adsorption experiments, the stock solution was diluted as necessary.

\subsection{Preparation of Natural Adsorbent}

An appropriate amount of biomass WP was centrifuged at $800 \mathrm{rpm}$ for $20 \mathrm{~min}$ at room temperature in order to separate the liquid oil from the solid residue. The solid material was mixed with n-hexane to eliminate the trace of oil and WAS dehydrated by ethanol. The solid material was stored in a dryer until constant mass. The separation yield of the solid biomass was about $30 \%$. Herein, we will refer to it as natural adsorbent.

\subsection{Preparation of Treated Adsorbent}

LAP (2.000 g) was dispersed into $0.200 \mathrm{dm}^{3}$ of UPW and the mixture was stirred at $350 \mathrm{rpm}$. Then, $5.00 \mathrm{~g}$ of natural adsorbent was added and the mixture was stirred continuously for about 3 days. Finally, the sample was collected into tubes and centrifuged at $8000 \mathrm{rpm}$ for $20 \mathrm{~min}$. The centrifuged solid was dried in an oven at $60{ }^{\circ} \mathrm{C}$ for about 2 days. The dry solid was pounded in a mortar until an apparently homogeneous powder was obtained. Hereafter, we will label this composite as WPLAP.

In order to carry out adsorption measurements, $2.5 \mathrm{~g}$ of LAPWPwas placed in a flask and mixed with $0.250 \mathrm{dm}^{3}$ of $\mathrm{K}_{2} \mathrm{CrO}_{4}$ solution at $48.1 \mu \mathrm{M}$. The $\mathrm{pH}$ of the resulting mixture was 7.20. Other measurements were performed by preparing the mixture with the same procedure, namely keeping both the initial chromium concentration and solution volume fixed, but using 1.5, 5.0 and $10 \mathrm{~g}$ of adsorbent. In order to evaluate the effect of LAP on $\mathrm{Cr}(\mathrm{VI})$ uptake, kinetic measurements with $2.5 \mathrm{~g}$ of adsorbent were carried out in parallel both with treated and natural biomass. 
The thermal analysis equipment consisted of a DSC-TG unit, TA Instruments Model Q-600. An empty platinum crucible served as a reference. A heating rate of $10^{\circ} \mathrm{C} \mathrm{min}-1$ was used during all the experiments. The samples were analyzed in dry nitrogen at $100 \mathrm{~mL} \mathrm{~min}^{-1}$ in the temperature range $20-900{ }^{\circ} \mathrm{C}$. The sample mass was around $15-25 \mathrm{mg}$ in all the experiments.

\subsection{Uptake Measurements}

All measurements were performed at $25^{\circ} \mathrm{C}$ and the $\mathrm{Cr}(\mathrm{VI})$ concentration decrease was determined by a UV/vis spectrophotometer Cary 100-Varian equipped with thermostated cells. For every investigated system, absorption spectra were recorded at room temperature in the 200-800 wavelength region and $\mathrm{Cr}(\mathrm{VI})$ was calculated from the area under each spectrum by applying the calibration curve method. Samples were in a shaking water bath vibrating at 30 oscillation per min. At regular intervals, $1 \mathrm{~mL}$ of solution was withdrawn, and the UV-visible spectrum was acquired and fed back into the initial solution. All uptake measurements were performed in duplicate and the accuracy was estimated by the mean root-mean-square error which was around $10-15 \%$. The amount of $\mathrm{Cr}(\mathrm{VI})$ adsorbed on the solid was obtained using the following matter balance formula:

$$
q_{A}=\frac{\left(C_{A}^{0}-C_{A}\right) V}{W}
$$

where $C_{A}\left(\mathrm{~mol} \cdot \mathrm{dm}^{-3}\right)$ and $C_{A}^{0}\left(\mathrm{~mol} \cdot \mathrm{dm}^{-3}\right)$ are the $\mathrm{Cr}(\mathrm{VI})$ concentration at time $t$ and 0 , respectively, and $V\left(\mathrm{dm}^{3}\right)$ is the solution volume and $W(\mathrm{~g})$ the adsorbent mass.

\section{Diffusion-Binding Model}

Considering a mass $m$ of the adsorbent, which is suspended in $\mathrm{K}_{2} \mathrm{CrO}_{4}$ solution of concentration $C_{0}$, the adsorbate diffuses into the solid and is adsorbed on the interior surface area. The rate accumulation in the solid results [15]:

$$
\frac{\partial C_{A}}{\partial t}+\left(-r_{A}\left(C_{A}\right)\right)=D_{A} \nabla^{2} C_{A}
$$

where $D_{A}$ is the diffusion coefficient of $\mathrm{Cr}(\mathrm{VI})$ ion in solution, $t$ is the time, and $\nabla^{2}$ is the Laplacian operator. The reaction term, $r_{A}\left(C_{A}\right)$ is an empirical expression. In general, the Laplacian operator involves all three spatial coordinates, however, we will mainly be concerned with systems where the symmetry allows this diffusion term to be written as a function of a single spatial coordinate.

$\mathrm{Cr}(\mathrm{VI})$ ions penetrate the pores of the composite, diffuse into the solid and bind to specific sites. We assume that the binding process is described by the following reaction [16]:

$$
A+S \rightleftarrows A S
$$

where $A, S$ and $A S$ represent $\mathrm{Cr}(\mathrm{VI})$, adsorption site, and complex $\mathrm{Cr}(\mathrm{VI})$-solid, respectively. Therefore, one can write:

$$
-r_{A}=\frac{d C_{A S}}{d t}=k_{1} C_{A} C_{S}-k_{-1} C_{A S}
$$

where $C_{A}(z, t)$, i.e. the concentration at position $z$ and time $t$ in the solid, assumes the form:

$$
\frac{\partial C_{A}}{\partial t}+\frac{d C_{A S}}{d t}=D_{A} \frac{\partial^{2} C_{A}}{\partial z^{2}}
$$

In order to solve this differential equation, a relationship between $C_{A S}$ and $C_{A}$ must exist.

Let:

$$
C_{A S}=f\left(C_{A}\right)
$$


then, Equation (5) becomes:

$$
\frac{\partial C_{A}}{\partial t}=\frac{D_{A}}{1+\frac{d f}{d C_{A}}} \frac{\partial^{2} C_{A}}{\partial z^{2}}
$$

Actual solid concentration is related to $C_{A S}$ by the matter balance, thus:

$$
C_{S}^{0}=C_{S}+C_{A S}
$$

Since the binding reaction proceeds very rapidly compared with the pore diffusion, we made the assumption that a local steady state

$$
\frac{d C_{A S}}{d t} \simeq 0
$$

and consequently, we have:

$$
f\left(C_{A}\right)=\frac{K_{1} C_{1} C_{S}^{0}}{K_{-1}+K_{1} C_{A}}=\frac{K C_{1} C_{S}^{0}}{1+K C_{A}}
$$

where $K=\frac{k_{1}}{k_{-1}}$ has been used.

Substitution of Equation (9) into Equation (7), yields:

$$
\frac{\partial C_{A}}{\partial t}=\left[\frac{D_{A}}{1+\frac{K C_{S}^{0}}{\left(1+K C_{A}\right)^{2}}}\right] \frac{\partial^{2} C_{A}}{\partial z^{2}}
$$

At low penetrant concentration $K C_{A} \ll 1$ so that Equation (10) can be rewritten as

$$
\frac{\partial C_{A}}{\partial t}=\bar{D} \frac{\partial^{2} C_{A}}{\partial z^{2}}
$$

Equation (11) describes the rate of change in $\mathrm{Cr}(\mathrm{VI})$ concentration in terms of an effective diffusion coefficient, defined as

$$
\bar{D}=\frac{D_{A}}{1+K C_{S}^{0}}
$$

where it is evident that the binding to specific sites hinders the molecular diffusivity by the factor $1+K C_{S}^{0}$. Equation (11) has to be solved in some region such as $0<z<\ell$ with a given initial value of $C_{A}(z, t)$ at the instant $t=0$, and with boundary conditions at the ends of the region.

We seek a solution of Equation (11) in a solid sheet which satisfies the boundary and initial conditions:

$$
\begin{aligned}
\frac{\partial C_{A}}{\partial z} & =0 \text { for } x=0 \\
C_{A} & =C_{A}^{1} \text { for } x=\ell \\
C_{A} & =C_{A}^{0} \text { for for } 0<x<\ell
\end{aligned}
$$

For the sake of simplicity, we assume that the concentration at one end of the region reaches the equilibrium value, i.e., $C_{A}=C_{A}^{e}$. By applying the well-known method of variable separation [17], one finds the following solution:

$$
\frac{C_{A}-C_{A}^{0}}{C_{A}^{e}-C_{A}^{0}}=1-2 \sum_{j=0}^{\infty} \frac{(-1)^{j}}{\alpha_{j}} \cos \left(\frac{\alpha_{j} z}{\ell}\right) e^{-\frac{\bar{D} \alpha_{j}^{2}}{\ell^{2}} t}
$$

with $\alpha_{j}=(2 j+1) \frac{\pi}{2}$. 
Comparison with Equation (1) yields the following equation for the amount of A component adsorbed on the solid:

$$
\frac{q_{A}(z, t)}{q_{A \infty}}=1-2 \sum_{j=0}^{\infty} \frac{(-1)^{j}}{\alpha_{j}} \cos \left(\frac{\alpha_{j} z}{\ell}\right) e^{-\frac{\bar{D} \alpha_{j}^{2}}{\ell^{2}} t}
$$

By averaging over the entire solid, the uptake rate is determined:

$$
\frac{\bar{q}_{A}(t)}{q_{A \infty}}=1-2 \sum_{j=0}^{\infty} \frac{1}{\alpha_{j}^{2}} e^{-\alpha_{j}^{2} \frac{t}{\bar{\tau}_{D}}}
$$

where the diffusion lifetime [18]:

$$
\bar{\tau}_{D}=\frac{\ell^{2}}{\bar{D}}
$$

is introduced.

Finally, the substitution of Equation (12) into Equation (16), yields:

$$
\bar{\tau}_{D}=\tau_{A}\left(1+K C_{S}^{0}\right)
$$

with $\tau_{A}=\frac{\ell^{2}}{D_{A}}$.

Thus, the model predicts that the diffusion time against the adsorbent concentration increases linearly, at a low $\mathrm{Cr}(\mathrm{VI})$ concentration.

To simplify the application of Equation (15), we note that it can be further simplified:

$$
\frac{\bar{q}_{A}(t)}{q_{A \infty}}=\frac{4}{\sqrt{\pi}} \sqrt{\frac{t}{\overline{\bar{\tau}}_{D}}} \text { for } \quad \frac{t}{\overline{\bar{\tau}}_{D}} \leq \frac{1}{20}
$$

and:

$$
\frac{\bar{q}_{A}(t)}{q_{A \infty}}=1-\frac{8}{\pi^{2}} e^{-\frac{\pi^{2} t}{\bar{\tau}_{D}}} \quad \text { for } \quad \frac{t}{\bar{\tau}_{D}}>\frac{1}{20}
$$

\section{Results and Discussion}

\subsection{Thermal Characterization of Biomass WP}

As pointed out elsewhere, TG measurements within a group of specimens provide information about the structural change undergone by the material [19]. Figure 1a shows TG and DTG profiles for biomass WP measured in $\mathrm{N}_{2}$ atmosphere. The TG curve exhibits two main mass loss contributions. The first mass loss in the range of $20-200{ }^{\circ} \mathrm{C}$ has to be ascribed to water evaporation or the elimination of volatile substances. The second major mass loss in the range of $200-700{ }^{\circ} \mathrm{C}$ is due to pyrolysis. Although the TG curve in the pyrolysis region appears to show only one mass loss, the DTG curve shows three different peaks in this region. Such peaks can be more easily interpreted from the DSC curve, which is the result of the pyrolysis of the sample. Indeed, as one can see in Figure $1 \mathrm{~b}$, the first major peak, from room temperature to $165^{\circ} \mathrm{C}$, is due to the water amount and volatile compounds. The second peak around $290^{\circ} \mathrm{C}$ can be attributed to hemicellulose decomposition. The third peak centered at $330^{\circ} \mathrm{C}$ is ascribed to the cellulose decomposition. Finally, the fourth largest peak around $425^{\circ} \mathrm{C}$ is due to the lignin decomposition [20]. 

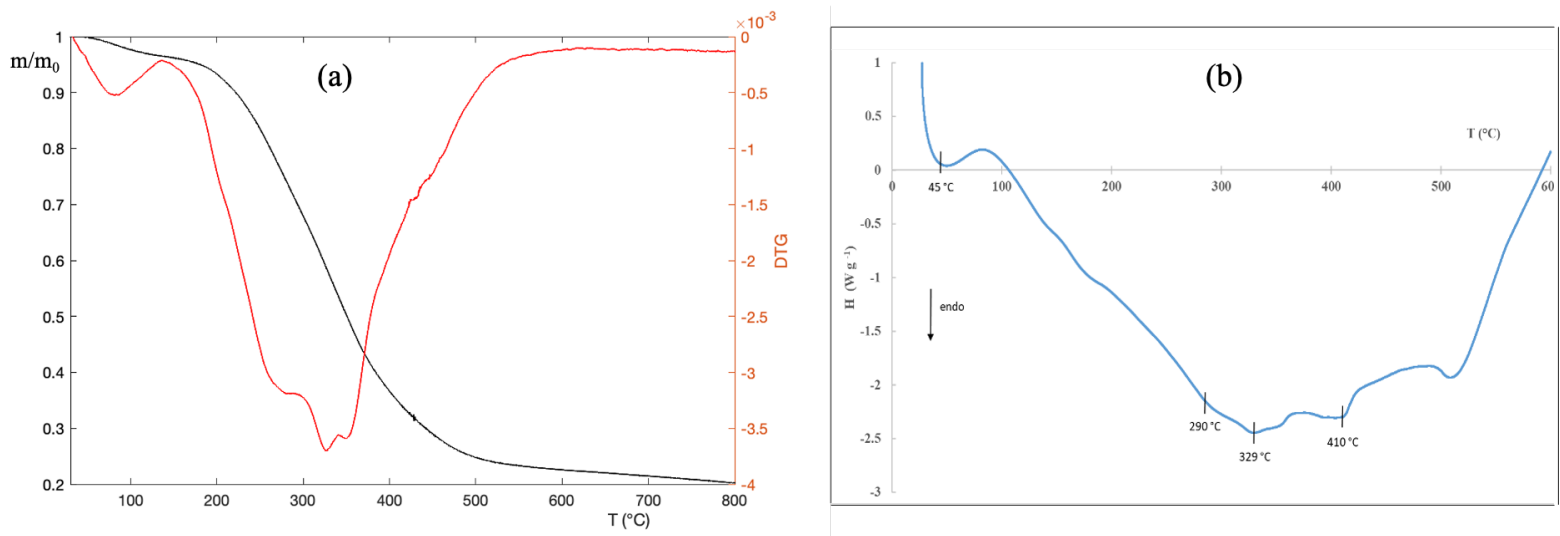

Figure 1. (a) TG and DTG curves of biomass WP. Measurements were performed under $\mathrm{N}_{2}$ stream $\left(100 \mathrm{~cm}^{3} \mathrm{~min}^{-1}\right)$ and at a heating rate of $10^{\circ} \mathrm{C} \min ^{-1} ;(\mathbf{b})$ the DSC profiles of biomass WP were obtained by measurements performed under $\mathrm{N}_{2}$ stream $\left(100 \mathrm{~cm}^{3} \mathrm{~min}^{-1}\right)$ and a heating rate of $10^{\circ} \mathrm{C} \mathrm{min}^{-1}$.

\subsection{Spectral Characterization of Cr(VI) Aqueous Solutions}

In aqueous solutions, $\mathrm{Cr}(\mathrm{VI})$ gives rise to different chemical equilibria involving various ionic species (speciation) [8,21]. In Figure 2a, the absorption spectra of $\mathrm{K}_{2} \mathrm{CrO}_{4}$, at $25^{\circ} \mathrm{C}$, for $0.96,1.92,3.85,7.69,9.61,19.6,50.0,76.9 \mu \mathrm{M}$ concentrations, were collected. It was immediately seen that, for each concentration investigated, the spectrum exhibited two distinct bands. Since at $\mathrm{pH}=7.6, \mathrm{CrO}_{4}{ }^{2-}$ and $\mathrm{HCrO}_{4}{ }^{-}$are the predominant species, the following equilibrium:

$$
\mathrm{CrO}_{4}{ }^{-2}+\mathrm{H}_{2} \mathrm{O} \rightleftarrows \mathrm{HCrO}_{4}^{-}+\mathrm{OH}^{-}
$$

can be considered as largely responsible for the spectra displayed in Figure 2a $[8,21]$.
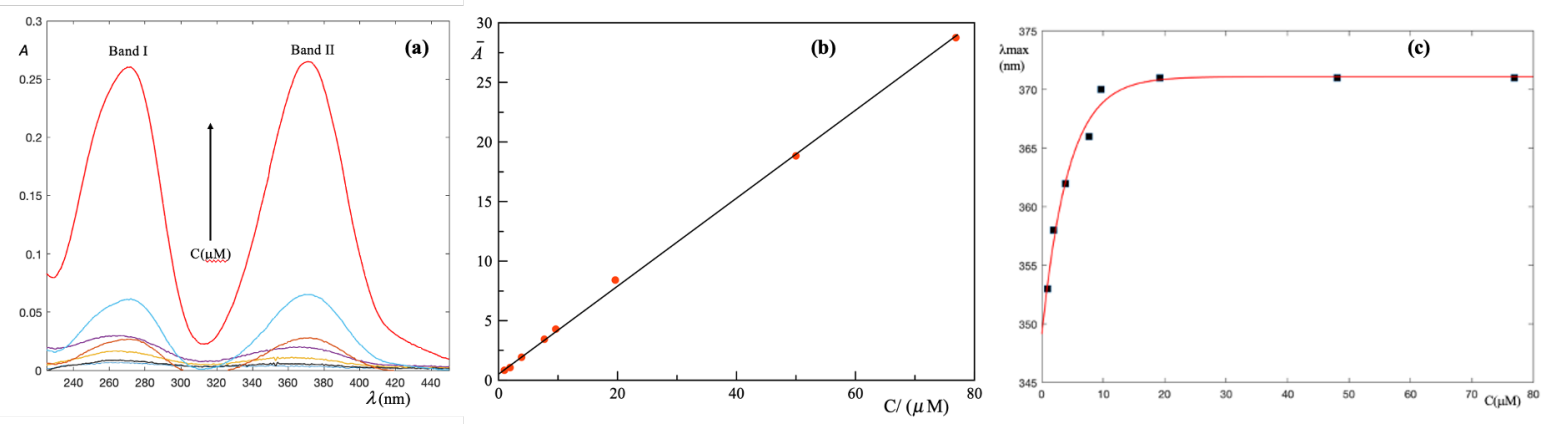

Figure 2. Results of the spectrophotometric measurements on aqueous solutions of $\mathrm{K}_{2} \mathrm{CrO}_{4}$ at different concentrations in the range of 0.960-76.9 $\mu \mathrm{M}$. (a) The absorption spectra show two distinct bands whose intensity increases with increasing $\mathrm{Cr}(\mathrm{VI})$ concentration; (b) the integral absorbance of the individual samples is a linear function of $\mathrm{Cr}(\mathrm{VI})$ concentration and can be used as a calibration line; (c) increasing $\mathrm{Cr}(\mathrm{VI})$ concentration of $\lambda_{\text {max }}$ of band II shifts to longer wavelengths and reaches a plateau.

Indeed, the electronic configuration of $\mathrm{Cr}(\mathrm{VI})$ is $3 \mathrm{~d}^{5} 4 \mathrm{~s}^{1}$ corresponding to a state $d^{0}$, then the probability of $\mathrm{d}-\mathrm{d}$ transitions is negligibly small. In addition, the formal charge on $\mathrm{Cr}$ atom $(+6)$ is very high so that electrons flow from $\mathrm{O}$ atoms to the $\mathrm{Cr}$ atom. In other words, both bands shown in the spectra of Figure 2a are the result of the charge transfer. If the molecular structure of the $\mathrm{CrO}_{4}{ }^{-2}$ ion is analyzed, one finds that it is perfectly symmetrical since the metal is surrounded by four perfectly equivalent $\mathrm{O}$ atoms. Hence, the representative band II is wide and centered in the range of 360-373 nm. On the contrary, in the $\mathrm{HCrO}_{4}{ }^{-}$molecule, the neutralization of an $\mathrm{O}$ atom reduces the symmetry and makes the charge transfer more energetic. As a result, the representative band I shifts to lower 
wavelengths and is displayed at $262 \mathrm{~nm}$. A careful inspection of Figure 2a reveals that increasing the $\mathrm{Cr}(\mathrm{VI})$ concentration, band I remains practically fixed while band II shifts to longer wavelengths.

Whilst it can be seen that only the peak wavelength, $\lambda_{\max }$ can hardly capture information about the molecular structure and it is convenient to refer to integral absorbance, this allows us to generalize Beer's law [22]. Mathematically, it assumes the following form:

$$
\bar{A}(C)=\int_{\lambda_{1}}^{\lambda_{2}} A(C, \lambda) d \lambda
$$

where $\lambda$ is a wavelength (in nm) within the experimental interval $\left[\lambda_{1}, \lambda_{2}\right]$ and $C$ is the $\operatorname{Cr}(\mathrm{VI})$ molar concentration. In Figure $2 \mathrm{~b}, \bar{A}(\mathrm{C})$ is plotted as a function of $\mathrm{Cr}(\mathrm{VI})$ concentration $(\mu \mathrm{M})$. The relationship between $\bar{A}$ and $C$ is established by fitting the first-degree polynomial, $\bar{A}=p_{1} C+p_{2}$, to experimental data. A linear least square method is used for determining the parameters $p_{1}$ and $p_{2}$ and the goodness of the fit is confirmed by a high correlation coefficient $R^{2}=0.99$. Accordingly, this polynomial is used as a calibration line to convert the integral absorbance into $\mathrm{Cr}(\mathrm{VI})$ concentration.

The effect of $\mathrm{Cr}(\mathrm{VI})$ concentration was studied by monitoring $\lambda_{\max }$, i.e., the wavelength corresponding to the maximum of band II, as a function of $C$. The results are displayed in Figure 2c. A detailed numerical analysis indicates that experimental results are well described by a saturation curve of the type:

$$
\lambda_{\max }=\frac{a C}{1+b C}
$$

where $C$ is the $\operatorname{Cr}(\mathrm{VI})$ molar concentration, and $a$ and $b$ are adjustable parameters.

It is immediately deduced that:

$$
\lim _{C \rightarrow \infty} \lambda_{\max }=\frac{a}{b}=372 \mathrm{~nm}
$$

In short, at a high $\mathrm{Cr}(\mathrm{VI})$ concentration, band II remains constantly centered at $\lambda_{\max }=372 \mathrm{~nm}$. It is worth noting that this value coincides with the theoretically established value for pure $\mathrm{CrO}_{4}{ }^{2-}$ [23]. On the contrary, at low $\mathrm{Cr}(\mathrm{VI})$ concentration, each ion is more effectively surrounded by water molecules which hydrate the $\mathrm{Cr}(\mathrm{VI})$ molecule more strongly, i.e., with a high energy content interaction, and the $\lambda_{\max }$ shifts towards lower values.

\subsection{Uptake Measurements}

Figure 3 shows $q(t)$ (for the sake of simplicity, the subscript A has been omitted) vs. the contact time between the $\mathrm{Cr}(\mathrm{VI})$ solution and either the LAPWP or natural adsorbent.

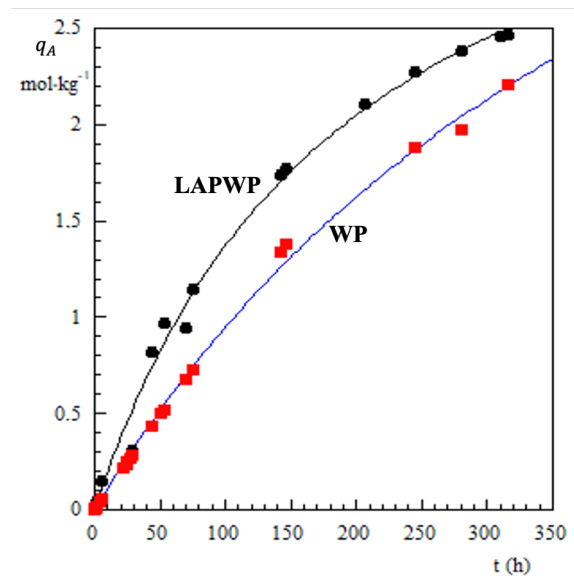

Figure 3. $\mathrm{Cr}(\mathrm{VI})$ adsorbed on natural biomass (red squares) (WP) and biomass treated with LAP(dark points), (LAPWP). 
The inspection of Figure 3 reveals that adsorption on LAPWP is faster than on natural adsorbent. Furthermore, the amount of chromium retained by LAPWP biomass is approximately $25 \%$ higher than natural adsorbent.

Dry biomass immersed into liquid water absorbs about $40 \%$ of its mass. Accordingly, one can estimate that the LAPWP sample contains about $0.4 \%$ LAP dispersed in the organic matrix. With this in mind, the experimental results displayed in Figure 3 must consider a synergistic effect between the LAP structure and biomass. Indeed, LAP particles are diskshaped with a thickness of $1 \mathrm{~nm}$ and a diameter of $25 \mathrm{~nm}$. In aqueous medium, at pH 7.6, the faces of the disks assume a negative charge, while the edges exhibit a positive charge [24]. Furthermore, at $\mathrm{pH}=7.6$, the biomass surface is slightly negative. Thus LAP-platelets orient their edges to bond with the biomass surface, causing a very extensive perturbation in its three-dimensional structure. This molecular rearrangement of biomass makes many more binding sites accessible for $\mathrm{CrO}_{4}{ }^{2-}, \mathrm{HCrO}_{4}{ }^{-}$ions. In other words, the synergistic interaction between LAP-platelets and the biomass surface produces a greater number of adsorption sites to the $\mathrm{Cr}(\mathrm{VI})$ species. Obviously, the individual molecules diffuse into the material before binding to the adsorption sites. Namely, the diffusion process plays a key role in understanding the synergic interaction between LAP and the organic matrix of the biomass. To gather information in this direction, uptake measurements were performed in the presence of 1.5, 2.5, 5 and $10 \mathrm{~g}$ of LAPWP adsorbent, while the $\mathrm{Cr}(\mathrm{VI})$ concentration $(48.1 \mu \mathrm{M})$ and the dispersion volume $\left(0.250 \mathrm{dm}^{3}\right)$ were kept constant. All of experimental results are presented in Figure 4 where $q(t)$ as a function of the contact time, $t$, is plotted, for each amount of LAPWP used.

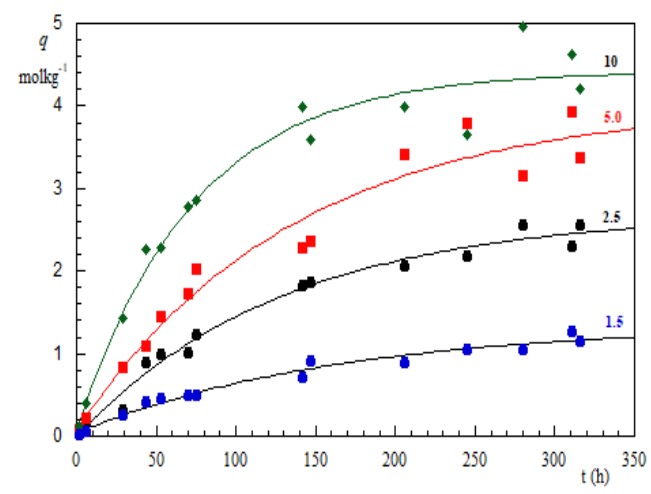

Figure 4. $\mathrm{Cr}(\mathrm{VI})$ amount adsorbed on biomass LAPWP as a function of the contact time. The number on each curve indicates the grams of LAPWP dispersed in $0.25 \mathrm{dm}^{3}$ of $\mathrm{Cr}(\mathrm{VI})$ solution at $48.1 \mu \mathrm{M}$. Each measurement was in duplicate and the root-mean-square error of the measurements was estimated to be $10-15 \%$.

It is evident that increasing the LAPWP mass increases the corresponding uptake curve. Such a trend is mostly attributed to an increase in the adsorbent surface area and the availability of more active binding sites on the surface of the adsorbent. Of course, to evaluate the role of diffusion, the term $q_{\infty}$ has to be determined. Here, we apply the procedure developed to extract the sedimentation limiting height from the experimental data [25].

It is empirically verified that a plot $q(t)$ vs. $t^{-1}$ exhibits a linear trend whereby $q_{\infty}$ was evaluated by a linear best-fit, as shown in Figure 5 . Having obtained $q_{\infty}$, the dimensionless ratio $q(t) / q_{\infty}$ is plotted as function of $t$, as shown in Figure 6a. 


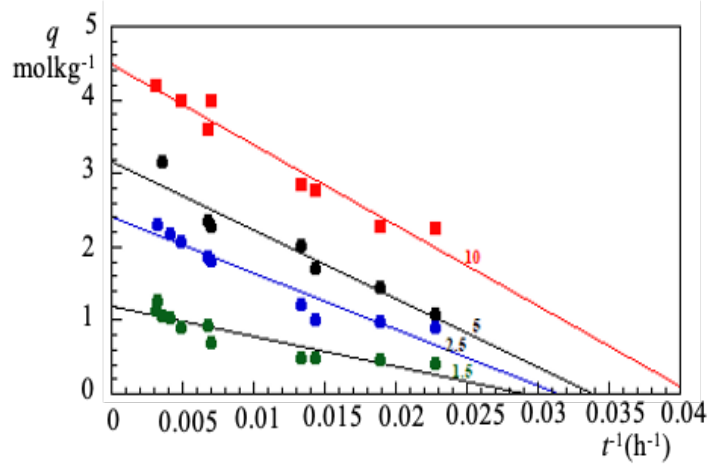

Figure 5. $\mathrm{Cr}(\mathrm{VI})$ amount adsorbed on biomass LAPWP as a function of the (contact time $)^{-1}$. The number on each curve indicates the grams of LAPWP dispersed in $0.25 \mathrm{dm}^{3}$ of $\mathrm{Cr}(\mathrm{VI})$ solution at $48.1 \mu \mathrm{M}$.The linearity of the experimental curve, for long contact times, allows the extrapolation of $q(t)$ at infinite time.
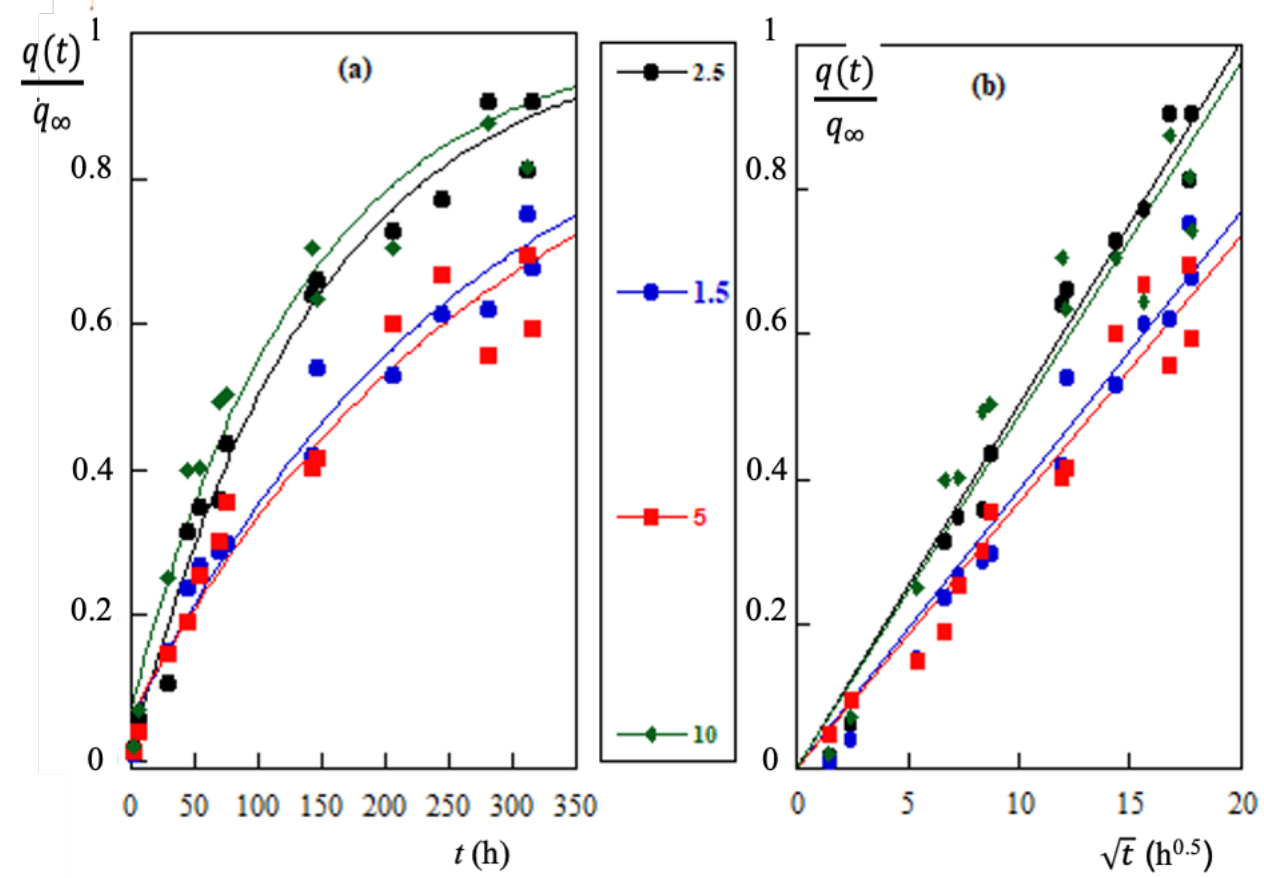

Figure 6. (a) Adsorption results of $\mathrm{Cr}(\mathrm{VI})$ on LAPWP adsorbent at $25{ }^{\circ} \mathrm{C}$, shown by continuous curves, represent the fitting of Equation (18) to the experimental data. (b) Adsorption results of $\mathrm{Cr}(\mathrm{VI})$ vs. $\sqrt{t}$. The linearity of plots indicates that the experimental data are well approximated by parabolic diffusion law. The numbers in the middle column represent the adsorbent mass $(\mathrm{g})$ dispersed in $0.25 \mathrm{dm}^{3}$ of $\mathrm{Cr}(\mathrm{VI})$ solution at $48.1 \mu \mathrm{M}$.

The curves are well fitted to Equation (19), that is to say the experimental values are in good agreement with what would be predicted by the diffusion-binding model. However, if the adsorption process is actually governed by diffusion, the ratio $q(t) / q_{\infty}$ has to verify the parabolic law of diffusion [17]. For this reason, the experimental values of Figure $6 a$ are also plotted as a function of $\sqrt{(} t)$ in Figure $6 \mathrm{~b}$. The straight line obtained confirms the prediction based on Equation (19), in other words, the diffusion-binding model explains the experimental results of $\mathrm{Cr}(\mathrm{VI})$ adsorption on LAPWP.

According to Equation (18), by the slope of lines in Figure 6b, one can calculate the lifetime $\bar{\tau}_{D}$. The results obtained are shown in Figure 7 as a function of the amount of LAPWP per volume unit $\left(C_{s}, \mathrm{gdm}^{-3}\right)$. 


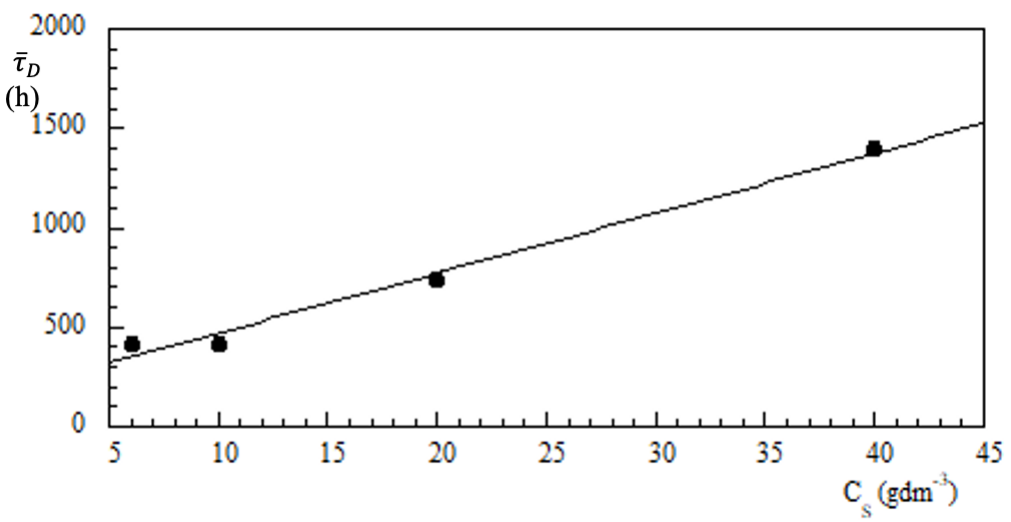

Figure 7. Diffusion lifetime vs. LAPWP concentration. Experiments were carried out in a volume of $0.25 \mathrm{dm}^{3}$ and an initial concentration of $\mathrm{Cr}(\mathrm{VI})$ of $48.1 \mu \mathrm{M}$.

The best-fit gives an intercept, i.e., $\tau_{A},=168 \mathrm{~h}$ and slope $=30 \mathrm{~h} \cdot \mathrm{dm}^{3} \cdot \mathrm{g}^{-1}$. This means that, when the volume is fixed at $1 \mathrm{dm}^{3}$, the diffusion time increases by $1800 \mathrm{~min}$ for each gram of LAPWP used in the adsorption process.

The molecular diffusion coefficient of $\mathrm{Cr}(\mathrm{VI})$ in water solution, $D_{A}$, at $C=48.1 \mu \mathrm{M}$, is calculated by literature equations [26]. Therefore, by assuming $D_{A}$, and the same in the material pores, we can estimate the increase in length that a $\mathrm{Cr}(\mathrm{VI})$ molecule undergoes (in $1 \mathrm{dm}^{3}$ of solution) per gram of material. In other words, letting $\Delta \ell$ be the diffusion length increment, we find $\Delta \ell=1.2 \mathrm{~cm}$ per gram of LAPWP. Namely, each gram of LAPWP produces an increase in the diffusion path of about $1 \mathrm{~cm}$. In other words, the path to reach the adsorption site lengthens by an average of $1 \mathrm{~cm}$. Of course, this does not mean that the material adsorbs less $\mathrm{Cr}(\mathrm{VI})$ because the total number of the sites increases.

\section{Conclusions}

A wet pomace was obtained from a two-phase continuous plant and thermally characterized. The biomass was treated with LAP and used as a solid adsorbent to remove $\mathrm{Cr}(\mathrm{VI})$ from aqueous solutions. Uptake measurements made on both WP and LAPWP biomass show that the treated biomass adsorbs about $25 \%$ more $\mathrm{Cr}(\mathrm{VI})$. The amount of LAP retained in the biomass was $0.4 \%$ of the mass. Then, a synergistic effect between the LAP platelets and the biomass surface is suggested. The synergy, i.e., the cooperativity [24] between the interactions, releases more adsorption sites for $\mathrm{CrO}_{4}{ }^{-2}$ and $\mathrm{HCrO}_{4}{ }^{-}$ions. In this process, intraparticle diffusion plays a key role in reaching the adsorption sites. Experimental results indicate that diffusion plays a fundamental role, so they can be interpreted on the basis of a simple diffusion-binding model. Diffusion lifetime, $\tau_{D}$, appears to be linearly correlated to the LAPWP concentration, indicating that in $1 \mathrm{dm}^{3}$ of $\mathrm{Cr}(\mathrm{VI})$ $48.1 \mu \mathrm{M}$ solution, the diffusion time increases by about $30 \mathrm{~h}$ for each gram of adsorbent. By assuming that the diffusion coefficient of $\mathrm{Cr}(\mathrm{VI})$ in water, $D_{A}$, remains the same even in the pores of the material, we estimated that the diffusion length increases by approximately $1 \mathrm{~cm}$ per gram of LAPWP. In other words, the distance traveled by a $\mathrm{Cr}(\mathrm{VI})$ molecule before being adsorbed increases by about $1 \mathrm{~cm}$ for each gram of LAPWP (in $1 \mathrm{dm}^{3}$ of solution). Obviously, this does not correspond to a decrease in $\mathrm{Cr}(\mathrm{VI})$ adsorbed because the total number of adsorption sites increases.

Author Contributions: Conceptualization, methodology, L.A.; software, M.P. formal analysis, M.P.; investigation, F.D.N.; data curation, G.B.; writing-original draft preparation, S.S.; project administration, L.A. All authors have read and agreed to the published version of the manuscript.

Funding: This research received no external funding.

Acknowledgments: The author thak Giuseppe D'Amato for the IT support during the drafting of the paper. 
Conflicts of Interest: The authors declare no conflict of interest.

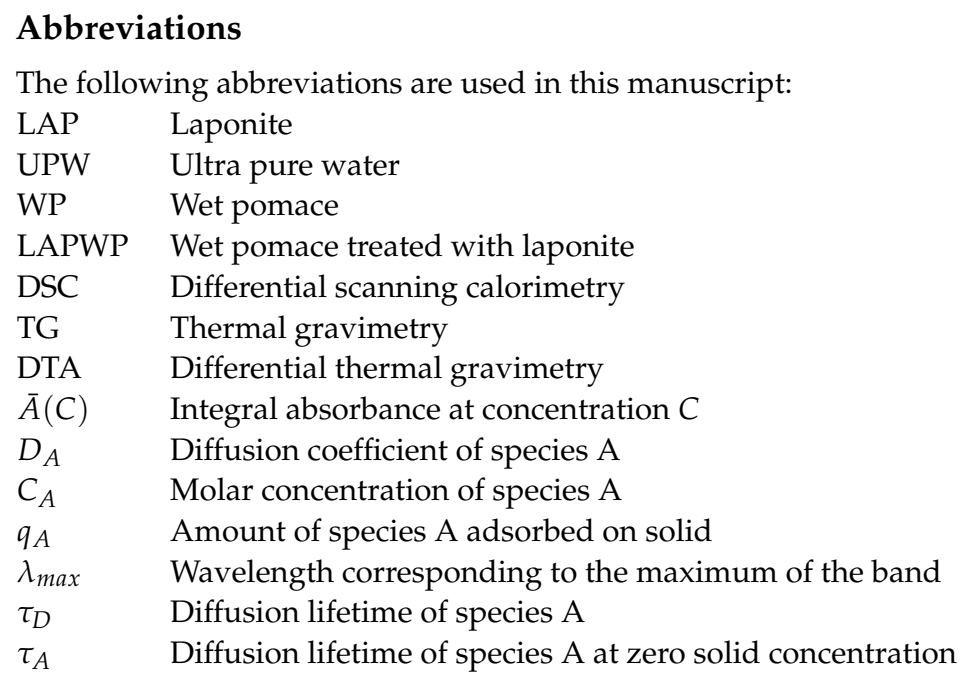

\section{References}

1. Boskou, D. Olive Oil: Chemistry and Technology; Boskou, D., Ed.; Elsevier: Amsterdam, The Netherlands, 2015.

2. Del Caro, A.; Vacca, V.; Poiana, M.; Fenu, P.; Piga, A. Influence of technology, storage and exposure on components of extra virgin olive oil (Bosana cv) from whole and de-stoned fruits. Food Chem. 2006, 98, 311-316. [CrossRef]

3. Morvová, M.; Onderka, M.; Morva, I.; Chudoba, V. Pyrolysis of olive mill waste with on-line and ex-post analysis. Waste Biomass Valorization 2019, 10, 511-520. [CrossRef]

4. Guida, M.Y.; Hannioui, A. A review on thermochemical treatment of biomass: Pyrolysis of olive mill wastes in comparison with other types of biomass. Prog. Agric. Eng. Sci. 2016, 12, 1-23. [CrossRef]

5. Ouazzane, H.; Laajine, F.; El Yamani, M.; El Hilaly, J.; Rharrabti, Y.; Amarouch, M.Y.; Mazouzi, D. Olive mill solid waste characterization and recycling opportunities: A review. Prog. Agric. Eng. Sci. 2017, 8, 2632-2650.

6. Dinc, G.; Isik, F.; Yel, E. Effects of Pyrolysis Conditions on Organic Fractions and Heat Values of Olive Mill Wastes Pyrolysis Liquid. J. Energy Resour. Technol. 2020, 142, 1-13

7. Martinez-Garcia, G.; Bachmann, R.T.; Williams, C.J.; Burgoyne, A.; Edyvean, R.G.J. Olive oil waste as a biosorbent for heavy metals. Int. Biodeterior. Biodegrad. 2006, 58, 231-238. [CrossRef]

8. Mosca, M.; Cuomo, F.; Lopez, F.; Palumbo, G.; Bufalo, G.; Ambrosone, L. Adsorbent properties of olive mill wastes for chromate removal. Desalin. Water Treat. 2015, 54, 275-283. [CrossRef]

9. Venditti, F.; Cuomo, F.; Ceglie, A.; Ambrosone, L.; Lopez, F. Effects of sulfate ions and slightly acidic pH conditions on Cr(VI) adsorption onto silica gelatin composite. J. Hazard. Mater. 2010, 173, 552-557. [CrossRef]

10. Al-Malah, K.; Azzam, M.O.J.; Abu-Lail, N.I. Olive mills effluent (OME) wastewater post-treatment using activated clay. Sep. Purif. Technol. 2000, 20, 225-234. [CrossRef]

11. Al Bsoul, A.; Hailat, M.; Abdelhay, A.; Tawalbeh, M.; Jum'h, I.; Bani-Melhem, K. Treatment of olive mill effluent by adsorption on titanium oxide nanoparticles. Sci. Total. Environ. 2019, 668, 1327-1334. [CrossRef]

12. Barbieri, L.; Andreola, F.; Lancellotti, I.; Taurino, R. Management of agricultural biomass wastes: Preliminary study on characterization and valorisation in clay matrix bricks. Waste Manag. 2013, 33, 2307-2315. [CrossRef]

13. Yuan, G. Natural and modified nanomaterials as sorbents of environmental contaminants. J. Environ. Sci. Health Part A 2004, 39, 2661-2670. [CrossRef]

14. Ochoa-Cornejo, F.; Bobet, A.; Johnston, C.; Santagata, M.; Sinfield, J.V. Dynamic properties of a sand-nanoclay composite. Géotechnique 2020, 70, 210-225. [CrossRef]

15. Di Nezza, F.; Caruso, C.; Costagliola, C.; Ambrosone, L. Reaction-diffusion model as framework for understanding the role of riboflavin in "eye defence" formulations. RSC Adv. 2020, 70, 14965-14971. [CrossRef]

16. Salvestrini, S. Analysis of the Langmuir rate equation in its differential and integrated form for adsorption processes and a comparison with the pseudo first and pseudo second order models. React. Kinet. Mech. Catal. 2018, 123, 455-472. [CrossRef]

17. Crank, J. The Mathematics of Diffusion; Oxford University Press: Great Britain, 1979.

18. Venditti, F.; Bufalo, G.; Lopez, F.; Ambrosone, L. Pollutants adsorption from aqueous solutions: The role of the mean lifetime. Chem. Eng. Sci. 2011, 23, 5922-5929. [CrossRef]

19. Bufalo, G.; Costagliola, C.; Mosca, M.; Ambrosone, L. Thermal analysis of milling products and its implications in self-ignition. J. Therm. Anal. Calorim. 2014, 1115, 1989-1998. [CrossRef]

20. Gomez-Martin, A.; Chacartegui, R.; Ramirez-Rico, J.; Martinez-Fernez, J. Performance improvement in olive stone's combustion from a previous carbonization transformation. Fuel 2018, 228, 254-262. [CrossRef] 
21. Fenti, A.; Chianese, S.; Iovino, P.; Musmarra, D.; Salvestrini, S. Cr(VI) Sorption from Aqueous Solution: A Review. Appl. Sci. 2020, 10, 6477. [CrossRef]

22. Di Nezza, F.; Guerra, G.; Lopez, F.; Ambrosone, L. Pollutants adsorption from aqueous solutions: The role of the mean lifetime. Dye. Pigment. 2016, 134, 342-347. [CrossRef]

23. Torrent, M.; Duran, M.; Solà, M. Theorethical study on the ground and excited states of Chromyl Fluoride (CrO2F2). Sci. Gerund. 1997, 23, 5-16.

24. Cinelli, G.; Guerra, G.; Bufalo, G.; Lopez, F.; Ambrosone, L. Cooperativity between Dimerization and Binding Equilibria in the Ternary System Laponite-Indocyanine Green-Water. ChemEngineering 2021, 5, 6. [CrossRef]

25. Molino, B.; Bufalo, G.; De Vincenzo, A.; Ambrosone, L. Semiempirical Model for Assessing Dewatering Process by Flocculation of Dredged Sludge in an Artificial Reservoir. Appl. Sci. 2020, 10, 3051. [CrossRef]

26. Iadicicco, N.; Paduano, L.; Vitagliano, V. Diffusion coefficients for the system potassium chromate-Water at $25^{\circ} \mathrm{C}$. J. Chem. Eng. Data 1996, 41, 529-533. [CrossRef] 